\title{
Le rôle des coordonnateurs régionaux de transplantation
}

Sept médecins (cinq anesthésistes réanimateurs à Lille, Lyon, Bordeaux, Rennes, Strasbourg, un chirurgien à Nice, un médecin à Paris) ont été nommés par le ministère de la Santé dans le cadre de FranceTransplant, détachés de leur poste de tutelle, à temps plein en 1982, pour deux ans, reconduits dans leur fonction à mi-temps pour deux ans en 1984 et en 1986. Ils ont quatre principales missions:

- Rôle incitateur : visites des centres de donneurs potentiels (rappel des besoins en organes, recommandations techniques et médicolégales), informations en retour sur le devenir des greffons prélevés, aide à aplanir les difficultés techniques administratives ou d'organisation locale. Ils parcourent ainsi plusieurs dizaines de milliers de kilomètres par an.

- Rôle informateur : information de l'administration et du public en vue de faire connaître et appliquer la Loi Caillavet, information des associations de malades et des associations de donneurs bénévoles (FFDOT).

- Rôle formateur: aide à la formation des coordonnateurs locaux de prélèvement.

- Rôle régulateur: aide à la coordination des prélèvements multi- organes, à la demande de l'équipe médico-chirurgicale.

La loi Caillavet autorise tout prélèvement, en l'absence de preuve ou témoignage traduisant que la personne en état de mort cérébrale s'y opposait.

Si le sujet est un mineur, le consentement des parents est requis.

Le "forfait greffon" est une prise en charge financière des dépenses inhérentes au prélèvement.

La nomination des coordonnateurs régionaux a été suivie d'un accroissement significatif de l'activité de greffe.

J. Hors

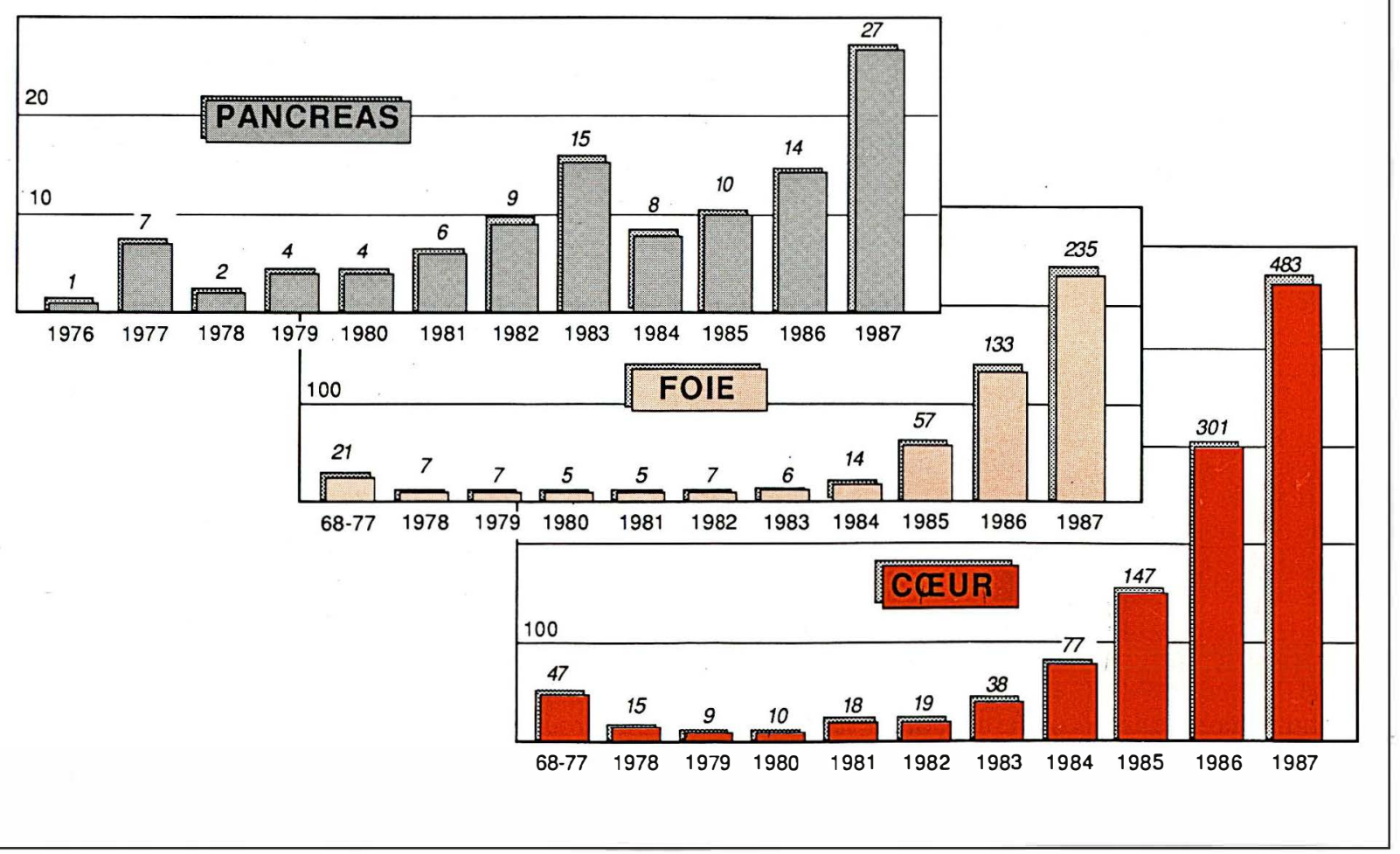

